DOI: 10.17707/AgricultForest.62.3.01

\author{
Virginia SARROPOULOU, \\ Kortessa DIMASSI-THERIOU, Ioannis THERIOS
}

\title{
MINERAL STRENGTH, SUCROSE LEVEL AND MANNITOL CONCENTRATION EFFECTS ON CHERRY ROOTSTOCKS MICROPROPAGATION
}

\begin{abstract}
SUMMARY
The aim of the present study was to investigate the effects of two strength media in inorganics (full and half), two sucrose levels (15 and $30 \mathrm{~g} / \mathrm{l}$ ) and four mannitol concentrations $(0,5,10,20 \mathrm{~g} / \mathrm{l})$ in combination with $1 \mathrm{mg} / \mathrm{l}$ indole-3butyric acid (IBA) on the morphogenic and biochemical responses in CAB-6P and Gisela 6 cherry rootstocks. In CAB-6P, root number (7.4) and rooting percentage $(83.33 \%)$ were maximum in half MS medium supplemented with 5 $\mathrm{g} / \mathrm{l}$ mannitol and $15 \mathrm{~g} / \mathrm{l}$ sucrose. Root length was greatest $(40.6 \mathrm{~mm})$ with $10 \mathrm{~g} / \mathrm{l}$ mannitol and $30 \mathrm{~g} / \mathrm{l}$ sucrose in full MS medium. In Gisela 6, in full MS medium, $20 \mathrm{~g} / \mathrm{l}$ mannitol $+15 \mathrm{~g} / \mathrm{l}$ sucrose exhibited the maximum root number (6.88), while $10 \mathrm{~g} / \mathrm{l}$ mannitol $+30 \mathrm{~g} / \mathrm{l}$ sucrose gave the greatest root length $(50.3 \mathrm{~mm})$. Rooting percentage was highest $(92.31 \%)$ in half $\mathrm{MS}+15 \mathrm{~g} / 1$ sucrose (mannitolfree) and in $10 \mathrm{~g} / \mathrm{l}$ mannitol $+15 \mathrm{~g} / \mathrm{l}$ sucrose (full MS) combination treatments. In CAB-6P, mannitol led to depleted chlorophyll, carotenoid and porphyrin levels in half MS medium for both sucrose levels. Mannitol resulted in elevated leaf and root carbohydrate as well as proline levels irrespective sucrose level and medium strength. In Gisela 6, mannitol +15 g/l sucrose decreased carotenoid content (full MS) and increased leaf proline content (half MS). In roots, $10 \mathrm{~g} / \mathrm{l}$ mannitol raised proline (full MS) and carbohydrate content (half MS) in both sucrose levels. Leaf carbohydrate content was higher in half MS medium supplemented with $30 \mathrm{~g} / \mathrm{l}$ sucrose. In both rootstocks, higher chlorophyll levels were recorded in half MS medium supplemented with $15 \mathrm{~g} / 1$ sucrose compared to the full MS one or with $30 \mathrm{~g} / \mathrm{l}$ sucrose. In full MS medium, increase of sucrose concentration led to depleted proline levels in Gisela 6 leaves and CAB-6P roots indicating activation of osmoregulation and osmotic adjustment mechanisms located in leaves for Gisela 6 and in roots for CAB-6P. An efficient root regeneration protocol and biochemical status evaluation of micropropagated cherry rootstocks shoot tips under the combined influence of different strength media, sucrose and mannitol concentrations was established.
\end{abstract}

Keywords: carbohydrates, in vitro rooting, mannitol, mineral salt composition, photosynthetic pigments, proline.

\footnotetext{
${ }^{1}$ Virginia Sarropoulou, (corresponding author: vsarrop@gmail.com), Kortessa Dimassi-Theriou, Ioannis Therios, Laboratory of Pomology, Department of Horticulture, School of Agriculture, Aristotle University of Thessaloniki, 54124 Thessaloniki, GREECE,

Notes: The authors declare that they have no conflicts of interest. Authorship Form signed online.
} 


\section{INTRODUCTION}

Growth and root initiation are high energy requiring processes that can only occur at the expense of available metabolic substrates, which are mainly carbohydrates (Calamar and De Klerk 2002). The establishment of effective shoot proliferation and root development in vitro is essential for subsequent success during acclimatization to autotrophic conditions (Premkumar et al. 2003). The addition of a carbon source in any nutrient medium is essential for in vitro growth and development of many species, because photosynthesis is insufficient, due to the growth taking place in conditions unsuitable for photosynthesis or without photosynthesis (in darkness) (Pierik, 1997).

In general, sucrose is the carbohydrate of choice as carbon source for in vitro plant culture, probably because it is the most common carbohydrate in the phloem sap of many plants (Fuentes et al., 2000) and because is cheap, readily available, relatively stable to autoclaving, and readily assimilated by plants (Fowler, 2000). It has also been well documented that certain plant tissues may contain and/or utilize different carbohydrates at the same time. It is then not surprising that carbon sources other than sucrose might be effective in promoting in vitro tissue specific growth responses in a given species (Swedlund and Locy 1993).

There are a number of species however that can grow on carbohydrates different than sucrose such as sorbitol, glycerol or mannitol (Vu et al. 1993).

In olive, mannitol is a major product of photosynthesis that reaches high concentrations in leaves that are second only to those of glucose and is translocated in the phloem (Flora and Madore 1993). Leva et al. (1995) have reported that mannitol improved the in vitro propagation of agamic olive explants, collected from mature trees growing in the field.

According to Ibrahim (1999), the concentration of inorganic salts plays an important role in root induction as it was shown that the reduction of MS salts strength to $3 / 4$ of the original concentration stimulated root formation in date palm tissue culture. The mineral concentration of the culture medium affects rooting characteristics, and some researchers have proposed its reduction to half normal strength for rooting improvement (Dimassi-Theriou and Economou 1993).

Therefore, the objectives of this study was to evaluate the effects of mannitol concentration, medium composition in minerals and sucrose level under in vitro conditions on the rooting process, vegetative growth, callusing traits as well as on biochemical parameters such as photosynthetic pigments, carbohydrate metabolism and endogenous free proline accumulation in two cherry rootstocks, namely CAB-6P and Gisela 6 .

\section{MATERIAL AND METHODS}

Plant material and culture conditions

In this experiment, the effects of two different strength media in inorganics; full and half, two different sucrose levels; 15 and $30 \mathrm{~g} / \mathrm{l}$ and four 
different mannitol concentrations; $0,5,10$ and $20 \mathrm{~g} / \mathrm{l}$ in combination with $1 \mathrm{mg} / \mathrm{l}$ IBA on vegetative growth, rooting and callusing of CAB-6P (Prunus cerasus) and Gisela 6 (Prunus canescens x Prunus cerasus) cherry rootstocks were studied. Shoot tips, 1.5 to $2.5 \mathrm{~cm}$ long were obtained from previous in vitro subcultures and placed onto a MS (Murashige and Skoog 1962) culture medium. The $\mathrm{pH}$ value of the culture medium was adjusted to 5.8 and $6 \mathrm{~g} / \mathrm{l}$ agar was added prior to autoclaving at $121 \mathrm{oC}$ for $20 \mathrm{~min}$. The experiment was comprised of 16 treatments and each treatment included 13 replications for $\mathrm{CAB}-6 \mathrm{P}$ and 22 replications for Gisela 6 with one microcutting placed in each $25 \times 100 \mathrm{~mm}$ glass test tube with flat base that contained $10 \mathrm{ml}$ of the nutrient culture medium. Afterwards, the cultures were maintained at 21-23 oC under cool white fluorescent light (Phillips, $90 \mu \mathrm{mol} / \mathrm{m} 2 / \mathrm{s}$ ) with a 16-hour photoperiod. After six weeks of culture, records and measurements were taken for root number per rooted explant, root length $(\mathrm{mm})$, root fresh weight $(\mathrm{g})$, rooting percentage $(\%)$, shoot length and fresh weight of the initial explant (shoot tip without roots), callus fresh weight, callus induction frequency $(\%)$, total leaf chlorophyll $(a+b)$, carotenoid and porphyrin content, total carbohydrate and endogenous proline content in both leaves and roots.

\section{Chlorophyll determination}

For chlorophyll measurement, $0.1 \mathrm{~g}$ of frozen leaf material was taken and placed in glass test tubes of $25 \mathrm{ml}$ volume. Fifteen $\mathrm{ml}$ of $96 \%$ ethanol was added in each tube, which was covered with aluminum foil to reduce ethanol evaporation. The tubes were incubated in a water bath of $79.8 \mathrm{oC}$, until complete sample discoloration and chlorophyll extraction. After chlorophyll extraction, the samples (tubes) were allowed to cool at room temperature and the level of $96 \%$ ethanol was completed to be $15 \mathrm{ml}$ volume. The absorbance of chlorophylls a and b was measured at 665 and $649 \mathrm{~nm}$, respectively, in a visible spectrophotometer. Chlorophyll concentration was determined according to Wintermans and De Mots (1965) from the following equations:

$\mathrm{Chl}(\mathrm{a}+\mathrm{b})=(6.10 \times \mathrm{A} 665+20.04 \times \mathrm{A} 649) \times 15 / 1000 / \mathrm{FW}(\mathrm{mg} / \mathrm{g} \mathrm{FW})$

$\mathrm{Chl}(\mathrm{a}+\mathrm{b})=(6.10 \times \mathrm{A} 665+20.04 \times \mathrm{A} 649) \times 15 / 1000 / \mathrm{DW}(\mathrm{mg} / \mathrm{g} \mathrm{DW})$

\section{Proline determination}

Leaf or root frozen tissue $(0.1 \mathrm{~g})$, was chopped into small pieces and placed in glass test tubes of $25 \mathrm{ml}$. In each tube, $10 \mathrm{ml}$ of $80 \%$ (v/v) ethanol was added and placed in a water bath of $60 \mathrm{oC}$ for $30 \mathrm{~min}$ (Khan et al. 2000). The tubes were covered with aluminum foil to reduce evaporation. The extracts were filtered and $80 \%$ (v/v) ethanol was added until the total volume (ethanol extract) to be $15 \mathrm{ml}$. After extraction, the aluminum foil was removed and the tubes were allowed to cool at room temperature. In each tube, $4 \mathrm{ml}$ of toluene was added and mixed well with a vortex. Two layers were visible in each tube. The supernatant (toluene layer) was removed with a pasteur pipette and was placed in a glass 
cuvette. The optical density of the extract was measured at $518 \mathrm{~nm}$. The extract was filtered with Whatman No. 1 filter paper and free proline was measured (Troll and Lindsley 1955) with acid ninhydrin solution. Proline concentrations were calculated from a standard curve by using L-proline (Sigma Chemical Company) at 0-0.2 $\mathrm{mM}$ concentrations.

\section{Carbohydrate determination}

Carbohydrate determination of plant tissue was conducted by using the anthrone method (Plummer, 1987). For reagent preparation, 1g of anthrone was diluted to $500 \mathrm{ml}$ concentrated sulfuric acid (96\%). The extract (plant ethanolic extract) for carbohydrate determination was the same as that used for proline, with the only difference that it was diluted 10 times with $80 \%$ (v/v) of ethanol. In each test tube, $2 \mathrm{ml}$ of anthrone reagent were placed and maintained in an ice bath. Subsequently, the diluted extract (10\% of the initial) was added dropwise in contact with the test tube walls in order to avoid blackening of the samples. After shaking the tubes with a vortex, the samples were incubated in a water bath of 95 oC for 15 min. Afterwards, the tubes were placed in a cold water bath for cooling and optical density was measured at $625 \mathrm{~nm}$. Carbohydrate concentrations were calculated from a standard curve by using $0-0.2 \mathrm{mM}$ sucrose concentrations.

\section{Carotenoid and porphyrin content measurement}

Carotenoid and porphyrin concentrations were determined as decribed Lichenthaler (1987) and Porra et al. (1989) and modified by Yang et al. (1998). Five milligrams of samples were homogenized with $5 \mathrm{ml}$ of $80 \%$ acetone in a cooled mortar. Extract was centrifuged for $5 \mathrm{~min}$ at 1,500 g, and the supernatant was stored. The pellet was re-extracted with acetone and centrifuged again. This process was continued until the supernatant was colourless, and then the supernatant was pooled.

1. Absorbance was measured at $663.6,646.6$ and $440.5 \mathrm{~nm}$, the major absorption peaks of chlorophyll $\mathrm{a}$ and $\mathrm{b}$ and carotenoids, respectively. Carotenoids were calculated using the following equation: $(4.69 \times$ A440.5 -1.96 $\times$ A663.6 - $4.74 \times$ A646.6 $) \times$ volume of supernatant $(\mathrm{ml}) \times$ dilution factor $/$ sample weight $(\mathrm{g})$.

2. Absorbance was measured at $663.6,646.6,440.5,575,590$ and $628 \mathrm{~nm}$, the absorption peaks of chlorophyll a, chlorophyll $\mathrm{b}$, carotenoids, protoporphyrin, magnesium-protoporphyrin and protochlorophyllide, respectively. Porphyrin content was summed $(\mathrm{A}+\mathrm{B}+\mathrm{C})$ by the following three equations:

$\mathrm{A}=[(12.25 \times \mathrm{A} 663.6-2.55 \times \mathrm{A} 646.6) \times$ volume of supernatant $(\mathrm{ml}) \times$ diluted factor / sample weight $(\mathrm{g})] / 892 \times 1000$

$\mathrm{B}=[(20.31 \times \mathrm{A} 646.6-4.91 \times \mathrm{A} 663.6) \times$ volume of supernatant $(\mathrm{ml}) \times$ diluted factor / sample weight $(\mathrm{g})] / 906 \times 1000$ 
$\mathrm{C}=[(196.25 \times \mathrm{A} 575-46.6 \times \mathrm{A} 590-58.68 \times \mathrm{A} 628)+(61.81 \times \mathrm{A} 590-$ $23.77 \times \mathrm{A} 575-3.55 \times \mathrm{A} 628)+(42.59 \times \mathrm{A} 628-34.32 \times \mathrm{A} 575-7.25 \times \mathrm{A} 590)] \times$ volume of supernatant $(\mathrm{ml}) \times$ dilution factor $/$ sample weight $(\mathrm{g})$.

\section{$\underline{\text { Statistical analysis }}$}

The experimental layout was completely randomized and the experiment was repeated twice. Thus, the reported data are the means of the two experiments. The means were subjected to analysis of variance (ANOVA) and compared using the Duncan multiple-range test $(\mathrm{P}<0.05)$.

The experiment was a $2 \times 2 \times 4$ factorial with two different strength media in inorganics (full and half), two different sucrose levels (15 and $30 \mathrm{~g} / \mathrm{l})$ and four mannitol concentrations $(0,5,10,20 \mathrm{~g} / \mathrm{l})$ for each of the two studied cherry rootstocks (CAB-6P and Gisela 6). The main effect of factors (medium strength in inorganics, sucrose level and mannitol concentration) and their interactions for each cherry rootstock were determined by the General Linear Model (3-way ANOVA).

\section{RESULTS AND DISCUSSION}

Effect of medium strength in inorganics, sucrose level and mannitol concentration on rooting, vegetative growth and callus induction characteristics.

In CAB-6P, best rooting results in terms of root number per rooted explant (7.4), root fresh weight $(0.073 \mathrm{~g})$ and rooting percentage $(83.33 \%)$ were obtained with $5 \mathrm{~g} / \mathrm{l}$ mannitol and $15 \mathrm{~g} / \mathrm{l}$ sucrose in half strength medium (Figure $1 \mathrm{n}$ ). On the other hand, root length reached its maximum value $(40.6 \mathrm{~mm})$ with $10 \mathrm{~g} / \mathrm{l}$ mannitol and $30 \mathrm{~g} / \mathrm{l}$ sucrose in full strength medium (Table 1, Figure 1c). Regarding the vegetative growth of the explants, $5 \mathrm{~g} / \mathrm{l}$ mannitol and $30 \mathrm{~g} / \mathrm{l}$ sucrose in full strength medium gave the maximum shoot length $(22.31 \mathrm{~mm})$ (Figure 1b) whereas better results for shoot fresh weight were recorded in the absence of mannitol (Figure 1a). Callus fresh weight was maximum $(0.170 \mathrm{~g})$ when $5 \mathrm{~g} / \mathrm{l}$ mannitol was incorporated along with $30 \mathrm{~g} / \mathrm{l}$ sucrose into the full strength medium in inorganics. Callus induction frequency reached its maximum value (100\%) by adding $10 \mathrm{~g} / \mathrm{l}$ mannitol to the medium containing $30 \mathrm{~g} / \mathrm{l}$ sucrose irrespective of media composition in mineral salts (Figures 1c, 1k). The same maximum callus induction frequency $(100 \%)$ was achieved in half MS medium with $15 \mathrm{~g} / \mathrm{l}$ sucrose in the absence of mannitol (Table 2, Figure $1 \mathrm{~m}$ ).

In Gisela 6,20 g/l mannitol $+15 \mathrm{~g} / \mathrm{l}$ sucrose in full MS medium exhibited the greatest root number per rooted explant (6.88) (Figure 2h). Root length and root fresh weight were maximum $(50.3 \mathrm{~mm}$ and $0.134 \mathrm{~g})$ with 10 or $20 \mathrm{~g} / \mathrm{l}$ mannitol $+30 \mathrm{~g} / \mathrm{l}$ sucrose in full MS medium, respectively (Figures $2 \mathrm{c}, 2 \mathrm{~d}$ ). Rooting percentage was highest $(92.31 \%)$ with $10 \mathrm{~g} / \mathrm{l}$ mannitol $+15 \mathrm{~g} / \mathrm{l}$ sucrose in full MS medium (Figure $2 \mathrm{~g}$ ) as well as in the absence of mannitol with $15 \mathrm{~g} / \mathrm{l}$ sucrose in half MS medium (Table 1, Figure $2 \mathrm{~m}$ ). 


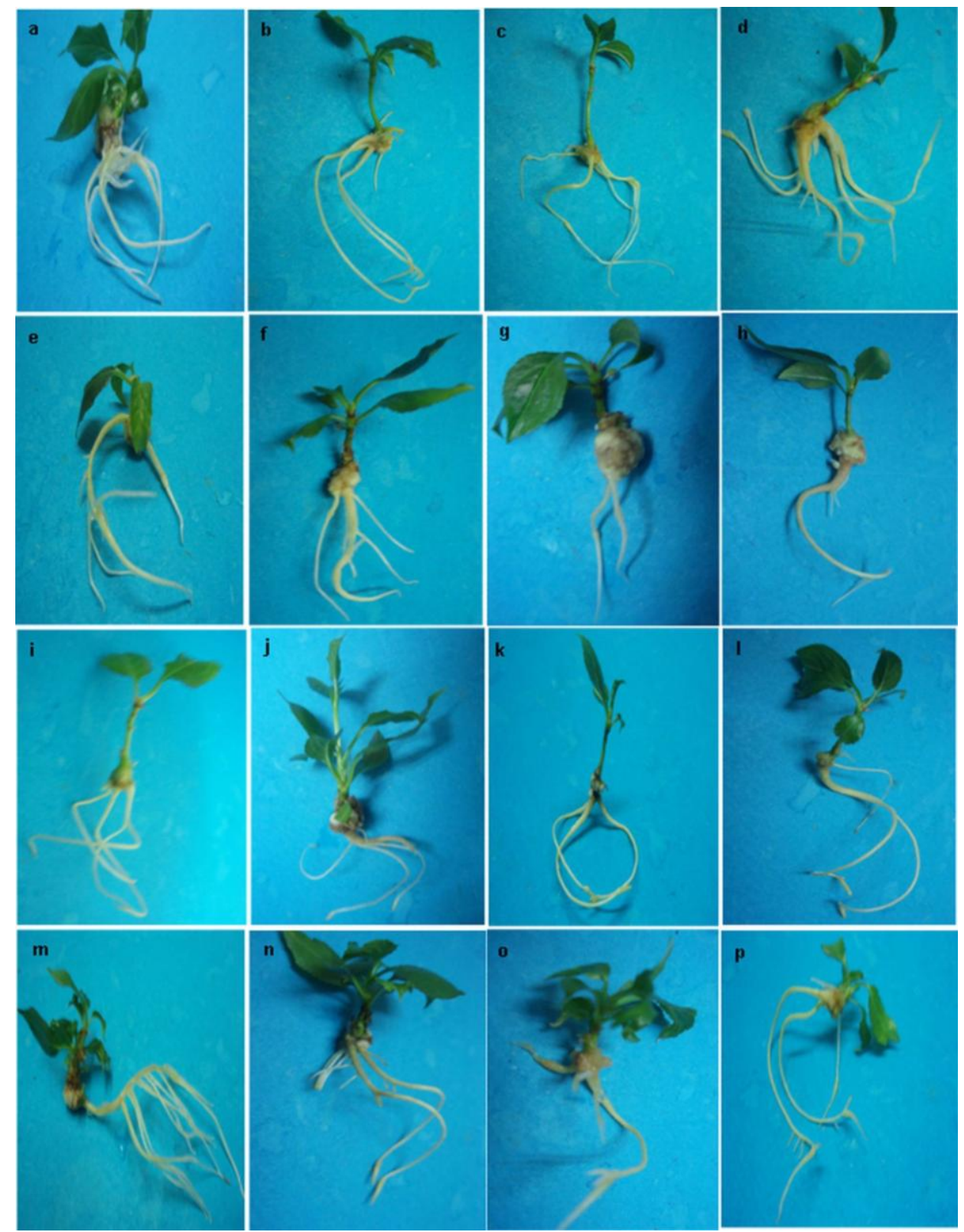

Figure 1 Effect of MS medium strength in inorganics, sucrose level and mannitol concentration combined with $1 \mathrm{mg} / \mathrm{l} \mathrm{IBA}$ on in vitro rooting of CAB-6P explants: (a) Full MS $+30 \mathrm{~g} / \mathrm{l}$ sucrose, (b) Full MS + 30 g/l sucrose +5 g/l mannitol, (c) Full MS + 30 g/l sucrose +10 g/l mannitol, (d) Full MS + $30 \mathrm{~g} / \mathrm{l}$ sucrose $+20 \mathrm{~g} / \mathrm{l}$ mannitol, (e) Full MS + $15 \mathrm{~g} / \mathrm{l}$ sucrose, (f) Full MS + $15 \mathrm{~g} / \mathrm{l}$ sucrose $+5 \mathrm{~g} / \mathrm{l}$ mannitol, (g) Full MS + $15 \mathrm{~g} / \mathrm{l}$ sucrose + $10 \mathrm{~g} / \mathrm{l}$ mannitol, (h) Full MS + $15 \mathrm{~g} / \mathrm{l}$ sucrose $+20 \mathrm{~g} / \mathrm{l}$ mannitol, (i) half MS + $30 \mathrm{~g} / \mathrm{l}$ sucrose (j) half $\mathrm{MS}+30 \mathrm{~g} / \mathrm{l}$ sucrose $+5 \mathrm{~g} / \mathrm{l}$ mannitol, (k) half MS + $30 \mathrm{~g} / \mathrm{l}$ sucrose $+10 \mathrm{~g} / \mathrm{l}$ mannitol, (l) half $\mathrm{MS}+30 \mathrm{~g} / \mathrm{l}$ sucrose $+20 \mathrm{~g} / \mathrm{l}$ mannitol, (m) half MS + $15 \mathrm{~g} / \mathrm{l}$ sucrose, (n) half MS $+15 \mathrm{~g} / \mathrm{l}$ sucrose $+5 \mathrm{~g} / \mathrm{l}$ mannitol, (o) half $\mathrm{MS}+15 \mathrm{~g} / \mathrm{l}$ sucrose $+10 \mathrm{~g} / \mathrm{L}$ mannitol, (p) half MS $+15 \mathrm{~g} / \mathrm{l}$ sucrose $+20 \mathrm{~g} / \mathrm{l}$ mannitol. 
Mineral strength, sucrose level and mannitol concentration effects on cherry rootstocks...

Table 1. Effect of medium strength in inorganics, sucrose level, mannitol concentration and their interactions in a medium containing $1 \mathrm{mg} / \mathrm{l} \mathrm{IBA}$ on $\mathrm{CAB}-6 \mathrm{P}$ and Gisela 6 cherry rootstocks rooting characteristics.

\begin{tabular}{|c|c|c|c|c|c|c|}
\hline $\begin{array}{l}\text { Strength MS } \\
\text { In inorganics }\end{array}$ & $\begin{array}{c}\text { Sucrose } \\
(\mathrm{g} / 1)\end{array}$ & $\begin{array}{l}\text { Mannitol } \\
(\mathrm{g} / \mathrm{l})\end{array}$ & $\begin{array}{c}\text { Root number } \\
\text { /rooted explant }\end{array}$ & $\begin{array}{l}\text { Root length } \\
(\mathrm{mm})\end{array}$ & $\begin{array}{l}\text { Root fresh } \\
\text { weight }(g)\end{array}$ & $\begin{array}{c}\text { Rooting percentage } \\
(\%)\end{array}$ \\
\hline \multicolumn{7}{|c|}{ Rootstock: CAB-6P } \\
\hline \multirow{8}{*}{ full } & 30 & 0 & $2.79 \mathrm{abc}$ & $29.93 \mathrm{~cd}$ & $0.050 \mathrm{abcd}$ & $70.00 \mathrm{~h}$ \\
\hline & 30 & 5 & $2.43 \mathrm{ab}$ & $31.63 \mathrm{~d}$ & $0.038 \mathrm{ab}$ & $53.85 \mathrm{c}$ \\
\hline & 30 & 10 & $1.71 \mathrm{a}$ & $40.60 \mathrm{e}$ & $0.032 \mathrm{a}$ & $38.46 \mathrm{a}$ \\
\hline & 30 & 20 & $3.17 \mathrm{abc}$ & $26.46 \mathrm{bcd}$ & $0.037 \mathrm{ab}$ & $53.85 \mathrm{c}$ \\
\hline & 15 & 0 & $4.13 \mathrm{bcd}$ & $31.67 \mathrm{~d}$ & $0.068 \mathrm{de}$ & $80.00 \mathrm{j}$ \\
\hline & 15 & 5 & $4.43 \mathrm{~cd}$ & $22.00 \mathrm{bc}$ & $0.042 \mathrm{abc}$ & $53.85 \mathrm{c}$ \\
\hline & 15 & 10 & $5.13 \mathrm{de}$ & 25.34 bcd & 0.055 bcde & $66.67 \mathrm{f}$ \\
\hline & 15 & 20 & $2.71 \mathrm{abc}$ & $32.61 \mathrm{~d}$ & $0.061 \mathrm{cde}$ & $53.85 \mathrm{c}$ \\
\hline \multirow{8}{*}{$1 / 2$} & 30 & 0 & $3.30 \mathrm{abc}$ & $19.35 \mathrm{ab}$ & $0.036 \mathrm{ab}$ & $76.92 \mathrm{i}$ \\
\hline & 30 & 5 & $3.17 \mathrm{abc}$ & $22.08 \mathrm{bc}$ & $0.038 \mathrm{ab}$ & $46.15 \mathrm{~b}$ \\
\hline & 30 & 10 & $2.50 \mathrm{ab}$ & $11.33 \mathrm{a}$ & $0.030 \mathrm{a}$ & $61.54 \mathrm{e}$ \\
\hline & 30 & 20 & $3.33 \mathrm{abc}$ & $18.58 \mathrm{ab}$ & $0.037 \mathrm{ab}$ & $46.15 \mathrm{~b}$ \\
\hline & 15 & 0 & $6.44 \mathrm{ef}$ & $19.38 \mathrm{ab}$ & $0.052 \mathrm{abcde}$ & $69.23 \mathrm{~g}$ \\
\hline & 15 & 5 & $7.40 \mathrm{f}$ & $20.86 \mathrm{~b}$ & $0.073 \mathrm{e}$ & $83.33 \mathrm{k}$ \\
\hline & 15 & 10 & $4.40 \mathrm{~cd}$ & $18.35 \mathrm{ab}$ & $0.051 \mathrm{abcd}$ & $55.56 \mathrm{~d}$ \\
\hline & 15 & 20 & $3.00 \mathrm{abc}$ & $20.84 \mathrm{~b}$ & $0.035 \mathrm{ab}$ & $38.46 \mathrm{a}$ \\
\hline \multicolumn{7}{|c|}{ 3-wayANOVA } \\
\hline \multicolumn{3}{|c|}{ Strength MS (A) } & $0.000 *$ & $0.363 \mathrm{~ns}$ & $0.000^{* * * *}$ & $0.000 * * *$ \\
\hline \multicolumn{3}{|c|}{ Sucrose level (B) } & $0.018^{*}$ & $0.000 * * *$ & $0.089 \mathrm{~ns}$ & $0.000 * * *$ \\
\hline \multicolumn{3}{|c|}{ Mannitol concentration (C) } & $0.001 * *$ & $0.147 \mathrm{~ns}$ & $0.003 * *$ & $0.000 * * *$ \\
\hline \multicolumn{3}{|c|}{$(\mathrm{A})^{*}(\mathrm{~B})$} & $0.833 \mathrm{~ns}$ & $0.044^{*}$ & $0.535 \mathrm{~ns}$ & $0.000^{* * *}$ \\
\hline \multicolumn{3}{|c|}{$(\mathrm{A}) *(\mathrm{C})$} & $0.041 *$ & $0.158 \mathrm{~ns}$ & $0.421 \mathrm{~ns}$ & $0.000 * * *$ \\
\hline \multicolumn{3}{|c|}{$(\mathrm{B}) *(\mathrm{C})$} & $0.044 *$ & $0.295 \mathrm{~ns}$ & $0.371 \mathrm{~ns}$ & $0.000^{* * *}$ \\
\hline \multicolumn{3}{|c|}{$(\mathrm{A}) *(\mathrm{~B}) *(\mathrm{C})$} & $0.014 *$ & $0.003 * *$ & $0.139 \mathrm{~ns}$ & $0.000 * * *$ \\
\hline \multicolumn{7}{|c|}{ Rootstock: Gisela 6} \\
\hline \multirow{8}{*}{ full } & 30 & 0 & $3.87 \mathrm{~b}$ & $36.29 \mathrm{e}$ & $0.052 \mathrm{ab}$ & $68.18 \mathrm{~g}$ \\
\hline & 30 & 5 & $3.75 \mathrm{ab}$ & $36.81 \mathrm{e}$ & $0.066 \mathrm{abc}$ & $30.77 \mathrm{a}$ \\
\hline & 30 & 10 & $4.33 \mathrm{bc}$ & $50.30 \mathrm{f}$ & $0.088 \mathrm{~cd}$ & $42.86 \mathrm{~d}$ \\
\hline & 30 & 20 & $5.43 \mathrm{~cd}$ & $34.13 \mathrm{de}$ & $0.134 \mathrm{f}$ & $58.33 \mathrm{f}$ \\
\hline & 15 & 0 & $5.29 \mathrm{~cd}$ & $28.27 \mathrm{bcd}$ & $0.045 \mathrm{a}$ & $77.27 \mathrm{~h}$ \\
\hline & 15 & 5 & $5.80 \mathrm{de}$ & $26.10 \mathrm{abc}$ & 0.119 ef & $76.92 \mathrm{~h}$ \\
\hline & 15 & 10 & $3.75 \mathrm{ab}$ & $29.63 \mathrm{~cd}$ & $0.081 \mathrm{bcd}$ & $92.31 \mathrm{i}$ \\
\hline & 15 & 20 & $6.88 \mathrm{e}$ & $23.70 \mathrm{abc}$ & $0.100 \mathrm{de}$ & $66.67 \mathrm{~g}$ \\
\hline \multirow{8}{*}{$1 / 2$} & 30 & 0 & $3.40 \mathrm{ab}$ & $21.71 \mathrm{a}$ & $0.049 \mathrm{a}$ & $38.46 \mathrm{bc}$ \\
\hline & 30 & 5 & $3.11 \mathrm{ab}$ & $23.24 \mathrm{ab}$ & $0.049 \mathrm{a}$ & $69.23 \mathrm{~g}$ \\
\hline & 30 & 10 & $2.40 \mathrm{a}$ & $23.40 \mathrm{abc}$ & $0.041 \mathrm{a}$ & $41.67 \mathrm{~cd}$ \\
\hline & 30 & 20 & $3.00 \mathrm{ab}$ & $32.83 \mathrm{de}$ & $0.083 \mathrm{~cd}$ & $53.85 \mathrm{e}$ \\
\hline & 15 & 0 & $5.42 \mathrm{~cd}$ & $24.01 \mathrm{abc}$ & 0.096 cde & $92.31 \mathrm{i}$ \\
\hline & 15 & 5 & $5.80 \mathrm{de}$ & $22.60 \mathrm{ab}$ & $0.100 \mathrm{de}$ & $35.71 \mathrm{~b}$ \\
\hline & 15 & 10 & $3.64 \mathrm{ab}$ & $26.44 \mathrm{abc}$ & $0.067 \mathrm{abc}$ & $64.71 \mathrm{~g}$ \\
\hline & 15 & 20 & $5.33 \mathrm{~cd}$ & $20.51 \mathrm{a}$ & $0.087 \mathrm{~cd}$ & $69.23 \mathrm{~g}$ \\
\hline \multicolumn{7}{|c|}{ 3-wayANOVA } \\
\hline \multicolumn{3}{|c|}{ Strength MS (A) } & $0.000 * * *$ & $0.000 * * *$ & $0.001 * *$ & $0.001 * *$ \\
\hline \multicolumn{3}{|c|}{ Sucrose level (B) } & $0.000 * * *$ & $0.000 * * *$ & $0.004 * *$ & $0.001 * *$ \\
\hline \multicolumn{3}{|c|}{ Mannitol concentration (C) } & $0.000 * * *$ & $0.000 * * *$ & $0.000 * * *$ & $0.001 * *$ \\
\hline \multicolumn{3}{|c|}{$(\mathrm{A})^{*}(\mathrm{~B})$} & $0.028 *$ & $0.000 * * *$ & $0.002 * *$ & $0.001 * *$ \\
\hline \multicolumn{3}{|c|}{$(\mathrm{A}) *(\mathrm{C})$} & $0.009 * *$ & $0.014 *$ & $0.000 * * *$ & $0.001 * *$ \\
\hline & $*(\mathrm{C})$ & & $0.016^{*}$ & $0.000 * * *$ & $0.000 * * *$ & $0.001 * *$ \\
\hline$(\mathrm{A})$ & $(\mathrm{B}) *(\mathrm{C})$ & & $0.744 \mathrm{~ns}$ & $0.000 * * *$ & $0.215 \mathrm{~ns}$ & $0.001 * *$ \\
\hline
\end{tabular}

Means denoted by the same letter in each column and for each rootstock separately are not significantly different according to Duncan's multiple range test at $\mathrm{P} \leq 0.05$. ns - non significant effect $(\mathrm{P} \geq 0.05)$. Significant effects at $\mathrm{P} \leq 0.01(* *)$ or $0.001(* * *)$ according to 3 -way ANOVA $(\mathrm{n}=13$ for CAB-6P and $\mathrm{n}=22$ for Gisela 6). 


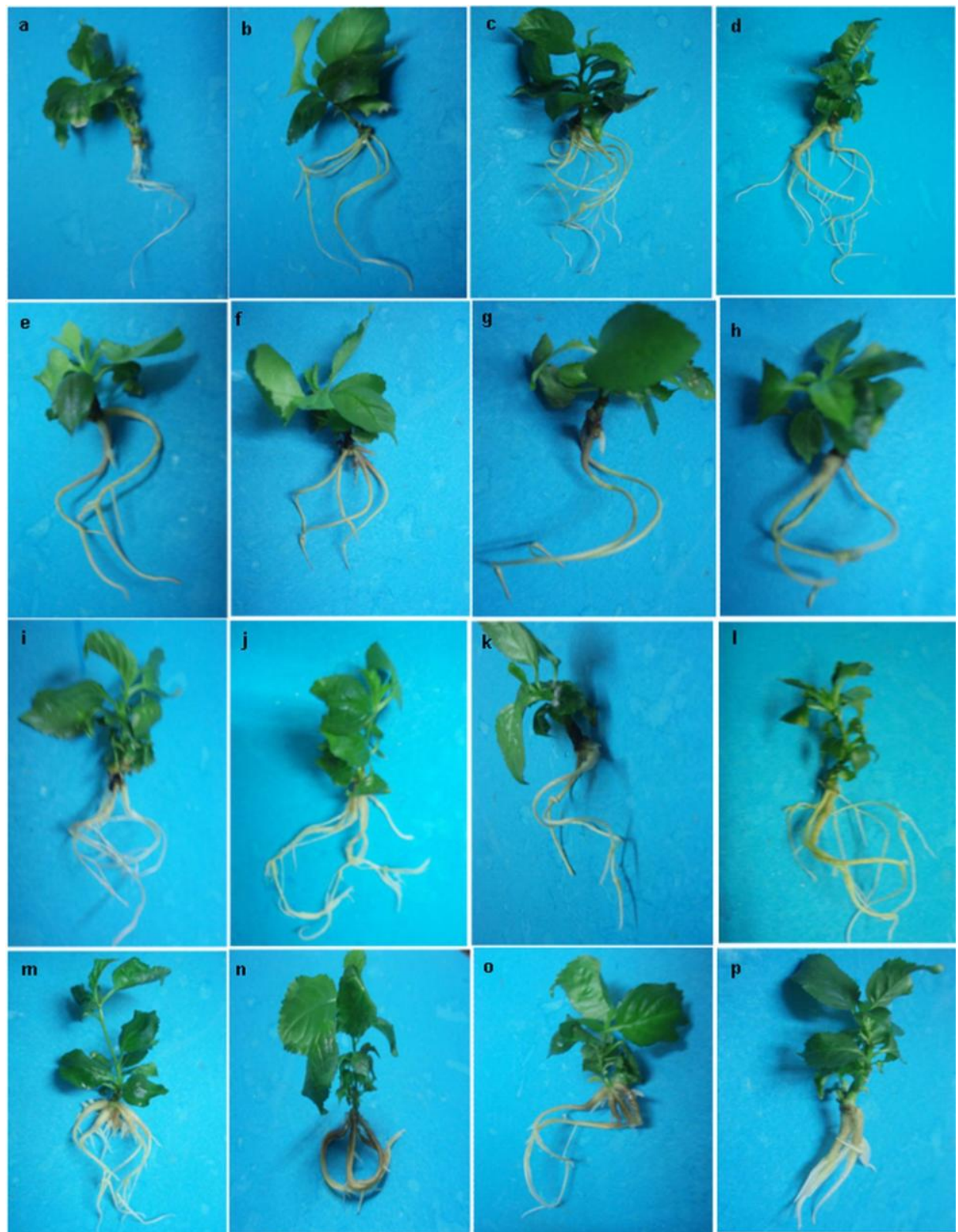

Figure 2 Effect of MS medium strength in inorganics, sucrose level and mannitol concentration combined with $1 \mathrm{mg} / \mathrm{l} \mathrm{IBA}$ on in vitro rooting of Gisela 6 explants: : (a) Full MS + $30 \mathrm{~g} / \mathrm{l}$ sucrose, (b) Full MS $+30 \mathrm{~g} / \mathrm{l}$ sucrose $+5 \mathrm{~g} / \mathrm{l}$ mannitol, (c) Full MS $+30 \mathrm{~g} / \mathrm{l}$ sucrose $+10 \mathrm{~g} / \mathrm{l}$ mannitol, (d) Full MS + 30 g/l sucrose + 20 g/l mannitol, (e) Full MS + 15 g/l sucrose, (f) Full MS $+15 \mathrm{~g} / \mathrm{l}$ sucrose $+5 \mathrm{~g} / \mathrm{l}$ mannitol, (g) Full MS + $15 \mathrm{~g} / \mathrm{l}$ sucrose $+10 \mathrm{~g} / \mathrm{l}$ mannitol, (h) Full MS + 15 $\mathrm{g} / \mathrm{l}$ sucrose $+20 \mathrm{~g} / \mathrm{l}$ mannitol, (i) half MS + $30 \mathrm{~g} / \mathrm{l}$ sucrose (j) half MS + $30 \mathrm{~g} / \mathrm{l}$ sucrose $+5 \mathrm{~g} / \mathrm{l}$ mannitol, (k) half MS + $30 \mathrm{~g} / \mathrm{l}$ sucrose $+10 \mathrm{~g} / \mathrm{l}$ mannitol, (l) half $\mathrm{MS}+30 \mathrm{~g} / \mathrm{l}$ sucrose $+20 \mathrm{~g} / \mathrm{l}$ mannitol, (m) half MS + $15 \mathrm{~g} / \mathrm{l}$ sucrose, (n) half MS $+15 \mathrm{~g} / \mathrm{l}$ sucrose $+5 \mathrm{~g} / \mathrm{l}$ mannitol, (o) half MS $+15 \mathrm{~g} / \mathrm{l}$ sucrose $+10 \mathrm{~g} / \mathrm{L}$ mannitol, (p) half $\mathrm{MS}+15 \mathrm{~g} / \mathrm{l}$ sucrose $+20 \mathrm{~g} / \mathrm{l}$ mannitol. 
Full strength medium in inorganics with $30 \mathrm{~g} / \mathrm{l}$ sucrose in the absence of mannitol $(24.09 \mathrm{~mm})$ (Figure 2a), full strength medium with $15 \mathrm{~g} / \mathrm{l}$ sucrose +20 $\mathrm{g} / \mathrm{l}$ mannitol $(23.33 \mathrm{~mm})$ (Figure $2 \mathrm{~h}$ ) and half strength medium with $15 \mathrm{~g} / \mathrm{l}$ sucrose $+5 \mathrm{~g} / \mathrm{l}$ mannitol $(23.21 \mathrm{~mm})$ (Figure $2 \mathrm{p}$ ) gave better results concerning shoot length.

In the absence of mannitol, half MS medium with $15 \mathrm{~g} / \mathrm{l}$ sucrose resulted in the maximum shoot $(0.190 \mathrm{~g})$ and callus fresh weight $(0.120 \mathrm{~g})$. Callus induction frequency was maximum (59.09\%) in full MS medium supplemented with $30 \mathrm{~g} / \mathrm{l}$ sucrose without mannitol (Table 2).

Effect of medium strength in inorganics, sucrose level and mannitol concentration on biochemical parameters

In CAB-6P, half MS medium $+15 \mathrm{~g} / \mathrm{l}$ sucrose (mannitol-free) and half MS medium $+30 \mathrm{~g} / \mathrm{l}$ sucrose $+5 \mathrm{~g} / \mathrm{l}$ mannitol exhibited the highest chlorophyll content.

Carotenoid and porphyrin content were greatest with $30 \mathrm{~g} / \mathrm{l}$ sucrose in half MS medium in devoid of mannitol (Table 3).

Adding $10 \mathrm{~g} / \mathrm{l}$ mannitol to the half MS medium with $30 \mathrm{~g} / \mathrm{l}$ sucrose led to elevated leaf carbohydrate levels. Proline content in leaves was maximum by applying $10 \mathrm{~g} / \mathrm{l}$ mannitol to full MS medium, irrespective sucrose level. In roots, 5 or $10 \mathrm{~g} / \mathrm{l}$ mannitol combined with $15 \mathrm{~g} / \mathrm{l}$ sucrose in full MS medium gave higher carbohydrate and proline content, respectively (Table 4).

In Gisela 6, chlorophyll content was higher by incorporating $10 \mathrm{~g} / \mathrm{l}$ mannitol $+30 \mathrm{~g} / \mathrm{l}$ sucrose or $15 \mathrm{~g} / \mathrm{l}$ sucrose without mannitol into the half MS medium. Treatment of explants in full MS medium supplemented with $15 \mathrm{~g} / \mathrm{l}$ sucrose resulted in the highest carotenoid content. On the other hand, medium strength in inorganics, sucrose level and mannitol concentration did not influence porphyrin content significantly (Table 3). Mannitol applied at $10 \mathrm{~g} / \mathrm{l}$ in half MS medium containing $30 \mathrm{~g} / \mathrm{l}$ sucrose led to elevated levels of carbohydrates in both leaves and roots. Leaf proline levels were higher by incorporating 5 or $10 \mathrm{~g} / \mathrm{l}$ mannitol into the $15 \mathrm{~g} / \mathrm{l}$ sucrose containing full MS medium. In the $10 \mathrm{~g} / \mathrm{l}$ mannitol+15 g/l sucrose+ full MS medium treatment, free root proline was remarkably increased (Table 4).

In both rootstocks, the 2-fold increase in sucrose level from 15 to $30 \mathrm{~g} / \mathrm{l}$ in both full and half MS media and in all mannitol concentrations resulted in higher root number. Similar results were obtained by Schneider (2005). In specific, half MS + $15 \mathrm{~g} / \mathrm{l}$ sucrose $+5 \mathrm{~g} / \mathrm{l}$ mannitol was the optimum treatment for root number and rooting percentage of CAB-6P microcuttings whereas the full MS + $15 \mathrm{~g} / \mathrm{l}$ sucrose $+20 \mathrm{~g} / \mathrm{l}$ mannitol treatment gave the highest root number in Gisela 6 explants. In the peach rootstock GF $677,30 \mathrm{~g} / \mathrm{l}$ sucrose gave better results regarding rooting percentage and root number, while lower $(15 \mathrm{~g} / \mathrm{l})$ and higher (45 and $60 \mathrm{~g} / \mathrm{l}$ ) concentrations had an inhibitory effect (Ahmad et al. 2007). Manzanera and Pardos (1990) found that rooting percentage and root number were enhanced with increasing sugar concentration. Therefore, the tendency to form roots under the highest sugar concentration may indicate an increase in water demands of these tissues. 
Table 2. Effect of medium strength in inorganics, sucrose level, mannitol concentration and their interactions in a medium containing $1 \mathrm{mg} / \mathrm{l} \mathrm{IBA}$ on CAB-6P and Gisela 6 cherry rootstocks on vegetative growth and callus induction characteristics.

\begin{tabular}{|c|c|c|c|c|c|c|}
\hline $\begin{array}{l}\text { Strength MS } \\
\text { in inorganics }\end{array}$ & $\begin{array}{c}\text { Sucrose } \\
(\mathrm{g} / 1)\end{array}$ & $\begin{array}{c}\text { Mannitol } \\
(\mathrm{g} / \mathrm{l})\end{array}$ & $\begin{array}{l}\text { Shoot length } \\
(\mathrm{mm})\end{array}$ & $\begin{array}{l}\text { Shoot fresh } \\
\text { weight }(\mathrm{g})\end{array}$ & $\begin{array}{l}\text { Callus fresh } \\
\text { weight }(\mathrm{g}) \\
\end{array}$ & $\begin{array}{c}\text { Callus induction } \\
\text { frequency }(\%)\end{array}$ \\
\hline \multicolumn{7}{|c|}{ Rootstock: CAB-6P } \\
\hline \multirow{8}{*}{ full } & 30 & 0 & $16.50 \mathrm{abc}$ & $0.124 \mathrm{f}$ & $0.070 \mathrm{abc}$ & $90.00 \mathrm{~h}$ \\
\hline & 30 & 5 & $22.31 \mathrm{~d}$ & $0.060 \mathrm{ab}$ & $0.085 \mathrm{bc}$ & $84.62 \mathrm{~g}$ \\
\hline & 30 & 10 & $18.85 \mathrm{~cd}$ & $0.056 \mathrm{a}$ & $0.089 \mathrm{bc}$ & $100 \mathrm{j}$ \\
\hline & 30 & 20 & $15.38 \mathrm{abc}$ & $0.071 \mathrm{ab}$ & $0.070 \mathrm{abc}$ & $61.54 \mathrm{~d}$ \\
\hline & 15 & 0 & $15.50 \mathrm{abc}$ & 0.111 def & $0.048 \mathrm{a}$ & $45.00 \mathrm{~b}$ \\
\hline & 15 & 5 & $18.46 \mathrm{bcd}$ & 0.090 bcde & $0.106 \mathrm{~cd}$ & $84.62 \mathrm{~g}$ \\
\hline & 15 & 10 & $17.50 \mathrm{abc}$ & $0.070 \mathrm{ab}$ & $0.073 \mathrm{abc}$ & $83.33 \mathrm{f}$ \\
\hline & 15 & 20 & $15.00 \mathrm{abc}$ & $0.084 \mathrm{abcd}$ & $0.068 \mathrm{ab}$ & $23.08 \mathrm{a}$ \\
\hline \multirow{8}{*}{$1 / 2$} & 30 & 0 & $17.31 \mathrm{abc}$ & $0.079 \mathrm{abc}$ & $0.125 \mathrm{de}$ & $92.31 \mathrm{i}$ \\
\hline & 30 & 5 & $18.08 \mathrm{bc}$ & $0.071 \mathrm{ab}$ & $0.170 \mathrm{f}$ & $92.31 \mathrm{i}$ \\
\hline & 30 & 10 & $17.69 \mathrm{abc}$ & $0.066 \mathrm{ab}$ & 0.142 ef & $100 \mathrm{j}$ \\
\hline & 30 & 20 & $15.38 \mathrm{abc}$ & $0.070 \mathrm{ab}$ & $0.087 \mathrm{bc}$ & $83.33 \mathrm{f}$ \\
\hline & 15 & 0 & $15.77 \mathrm{abc}$ & $0.081 \mathrm{abc}$ & $0.079 \mathrm{abc}$ & $100 \mathrm{j}$ \\
\hline & 15 & 5 & $17.08 \mathrm{abc}$ & 0.116 ef & $0.091 \mathrm{bc}$ & $58.33 \mathrm{c}$ \\
\hline & 15 & 10 & $13.33 \mathrm{a}$ & $0.066 \mathrm{ab}$ & $0.090 \mathrm{bc}$ & $44.44 \mathrm{~b}$ \\
\hline & 15 & 20 & $14.23 \mathrm{ab}$ & $0.070 \mathrm{ab}$ & $0.084 \mathrm{bc}$ & $76.92 \mathrm{e}$ \\
\hline \multicolumn{7}{|c|}{ 3-wayANOVA } \\
\hline \multicolumn{3}{|c|}{ Strength MS (A) } & $0.017 *$ & $0.001 * *$ & $0.000 * * *$ & $0.000 * * *$ \\
\hline \multicolumn{3}{|c|}{ Sucrose level (B) } & $0.030^{*}$ & $0.635 \mathrm{~ns}$ & $0.000 * * *$ & $0.000 * * *$ \\
\hline \multicolumn{3}{|c|}{ Mannitol concentration (C) } & $0.031 *$ & $0.000 * * *$ & $0.029 *$ & $0.000 * * *$ \\
\hline \multicolumn{3}{|c|}{$(\mathrm{A}) *(\mathrm{~B})$} & $0.932 \mathrm{~ns}$ & $0.273 \mathrm{~ns}$ & $0.003 * *$ & $0.000 * * *$ \\
\hline \multicolumn{3}{|c|}{$(\mathrm{A}) *(\mathrm{C})$} & $0.286 \mathrm{~ns}$ & $0.073 \mathrm{~ns}$ & $0.334 \mathrm{~ns}$ & $0.000 * * *$ \\
\hline \multicolumn{3}{|c|}{$(\mathrm{B}) *(\mathrm{C})$} & $0.012 *$ & $0.001 * *$ & $0.071 \mathrm{~ns}$ & $0.000 * * *$ \\
\hline \multicolumn{3}{|c|}{$(\mathrm{A}) *(\mathrm{~B}) *(\mathrm{C})$} & $0.848 \mathrm{~ns}$ & $0.644 \mathrm{~ns}$ & $0.046^{*}$ & $0.000 * * *$ \\
\hline \multicolumn{7}{|c|}{ Rootstock: Gisela 6} \\
\hline \multirow{8}{*}{ full } & 30 & 0 & $24.09 \mathrm{f}$ & $0.181 \mathrm{~cd}$ & $0.046 \mathrm{~cd}$ & $59.09 \mathrm{~h}$ \\
\hline & 30 & 5 & 19.62 bcde & $0.171 \mathrm{bcd}$ & $0.093 \mathrm{j}$ & $7.69 \mathrm{~b}$ \\
\hline & 30 & 10 & 19.64 bcde & $0.181 \mathrm{~cd}$ & $0.077 \mathrm{~h}$ & $7.14 \mathrm{~b}$ \\
\hline & 30 & 20 & 20.00 cde & $0.169 \mathrm{bcd}$ & $0.080 \mathrm{~h}$ & $8.33 \mathrm{~b}$ \\
\hline & 15 & 0 & 22.27 ef & $0.149 \mathrm{abc}$ & $0.039 \mathrm{~b}$ & $36.36 \mathrm{e}$ \\
\hline & 15 & 5 & $23.08 \mathrm{f}$ & $0.181 \mathrm{~cd}$ & $0.048 \mathrm{~d}$ & $7.69 \mathrm{~b}$ \\
\hline & 15 & 10 & $16.54 \mathrm{ab}$ & $0.140 \mathrm{ab}$ & $0.055 \mathrm{e}$ & $7.69 \mathrm{~b}$ \\
\hline & 15 & 20 & $23.33 \mathrm{f}$ & $0.147 \mathrm{abc}$ & $0.040 \mathrm{bc}$ & $16.67 \mathrm{c}$ \\
\hline \multirow{8}{*}{$1 / 2$} & 30 & 0 & $18.08 \mathrm{abc}$ & $0.179 \mathrm{~cd}$ & $0.044 \mathrm{bcd}$ & $23.08 \mathrm{~d}$ \\
\hline & 30 & 5 & $18.46 \mathrm{abcd}$ & $0.173 \mathrm{bcd}$ & $0.086 \mathrm{i}$ & $46.15 \mathrm{~g}$ \\
\hline & 30 & 10 & 20.00 cde & $0.171 \mathrm{bcd}$ & $0.070 \mathrm{~g}$ & $25.00 \mathrm{~d}$ \\
\hline & 30 & 20 & $15.77 \mathrm{a}$ & $0.148 \mathrm{abc}$ & $0.061 \mathrm{f}$ & $15.38 \mathrm{c}$ \\
\hline & 15 & 0 & $21.54 \mathrm{def}$ & $0.190 \mathrm{~d}$ & $0.120 \mathrm{k}$ & $7.69 \mathrm{~b}$ \\
\hline & 15 & 5 & $23.21 \mathrm{f}$ & $0.152 \mathrm{abc}$ & $0.067 \mathrm{~g}$ & $35.71 \mathrm{e}$ \\
\hline & 15 & 10 & $19.12 \mathrm{bcd}$ & $0.129 \mathrm{a}$ & $0.041 \mathrm{bc}$ & $41.18 \mathrm{f}$ \\
\hline & 15 & 20 & $18.85 \mathrm{bcd}$ & $0.119 \mathrm{a}$ & $0.000 \mathrm{a}$ & $\begin{array}{ll}0 & \mathrm{a} \\
\end{array}$ \\
\hline \multicolumn{7}{|c|}{ 3-wayANOVA } \\
\hline \multicolumn{3}{|c|}{ Strength MS (A) } & $0.002 * *$ & $0.000 * * *$ & $0.000 * * *$ & $0.000 * * *$ \\
\hline \multicolumn{3}{|c|}{ Sucrose level (B) } & $0.001 * *$ & $0.189 \mathrm{~ns}$ & $0.178 \mathrm{~ns}$ & $0.000 * * *$ \\
\hline \multicolumn{3}{|c|}{ Mannitol concentration (C) } & $0.000 * * *$ & $0.001 * *$ & $0.000 * * *$ & $0.000 * * *$ \\
\hline \multicolumn{3}{|c|}{$(\mathrm{A})^{*}(\mathrm{~B})$} & $0.028^{*}$ & $0.934 \mathrm{~ns}$ & $0.000 * * *$ & $0.063 \mathrm{~ns}$ \\
\hline \multicolumn{3}{|c|}{$(\mathrm{A}) *(\mathrm{C})$} & $0.000 * * *$ & $0.099 \mathrm{~ns}$ & $0.000 * * *$ & $0.000 * * *$ \\
\hline & $*(\mathrm{C})$ & & $0.000 * * *$ & $0.036^{*}$ & $0.000 * * *$ & $0.000 * * *$ \\
\hline & $\mathrm{B})^{*}(\mathrm{C})$ & & $0.229 \mathrm{~ns}$ & $0.117 \mathrm{~ns}$ & $0.000 * * *$ & $0.000 * * *$ \\
\hline
\end{tabular}

Means denoted by the same letter in each column and for each rootstock separately are not significantly different according to Duncan's multiple range test at $\mathrm{P} \leq 0.05$. ns - non significant effect $(\mathrm{P} \geq 0.05)$. Significant effects at $\mathrm{P} \leq 0.001$ (***) according to 3-way ANOVA ( $\mathrm{n}=13$ for CAB-6P and $\mathrm{n}=22$ for Gisela 6 ). 
Mineral strength, sucrose level and mannitol concentration effects on cherry rootstocks...

Table 3 Effect of medium strength in inorganics, sucrose level, mannitol concentration and their interactions in a medium containing $1 \mathrm{mg} / 1 \mathrm{IBA}$ on CAB-6P and Gisela 6 cherry rootstocks total leaf chlorophyll, carotenoid and porphyrin content.

\begin{tabular}{|c|c|c|c|c|c|}
\hline Strength MS in inorganics & $\begin{array}{c}\text { Sucrose } \\
(\mathrm{g} / \mathrm{l})\end{array}$ & $\begin{array}{c}\text { Mannitol } \\
(\mathrm{g} / \mathrm{l})\end{array}$ & $\begin{array}{c}\text { Chl(a+b) } \\
\text { (mg/g F.W.) }\end{array}$ & $\begin{array}{l}\text { Carotenoids } \\
\text { (mg/g F.W.) }\end{array}$ & $\begin{array}{l}\text { Porphyrins } \\
\text { (mg/g F.W.) }\end{array}$ \\
\hline \multicolumn{6}{|c|}{ Rootstock: CAB-6P } \\
\hline \multirow{8}{*}{ full } & 30 & 0 & 18.969 defg & 0.358 abcd & 5.990 cdef \\
\hline & 30 & 5 & 14.739 abcde & $0.460 \mathrm{de}$ & 5.794 bcde \\
\hline & 30 & 10 & $11.934 \mathrm{abcd}$ & 0.339 abc & $5.242 \mathrm{abc}$ \\
\hline & 30 & 20 & 19.294 defg & 0.389 abcd & $6.726 \mathrm{fg}$ \\
\hline & 15 & 0 & 15.068 bcde & 0.411 bcde & $5.451 \mathrm{abc}$ \\
\hline & 15 & 5 & 19.563 defg & $0.285 \mathrm{a}$ & $6.402 \mathrm{def}$ \\
\hline & 15 & 10 & $9.716 \mathrm{ab}$ & 0.336 abc & $5.004 \mathrm{a}$ \\
\hline & 15 & 20 & $21.550 \mathrm{efg}$ & $0.386 \mathrm{abcd}$ & $6.893 \mathrm{~g}$ \\
\hline \multirow{8}{*}{$1 / 2$} & 30 & 0 & 17.755 cde & $0.640 \mathrm{f}$ & $8.410 \mathrm{~h}$ \\
\hline & 30 & 5 & $22.879 \mathrm{fg}$ & $0.323 \mathrm{ab}$ & 6.217 defg \\
\hline & 30 & 10 & 15.177 bcde & $0.517 \mathrm{e}$ & $6.753 \mathrm{~g}$ \\
\hline & 30 & 20 & $7.267 \mathrm{a}$ & $0.377 \mathrm{abcd}$ & 5.832 bcde \\
\hline & 15 & 0 & $25.725 \mathrm{~g}$ & 0.451 cde & $6.813 \mathrm{~g}$ \\
\hline & 15 & 5 & $13.733 \mathrm{abcd}$ & 0.364 abcd & $5.662 \mathrm{abcd}$ \\
\hline & 15 & 10 & $17.627 \mathrm{cdef}$ & 0.413 bcde & $6.481 \mathrm{efg}$ \\
\hline & 15 & 20 & $10.918 \mathrm{abc}$ & 0.343 abc & $5.178 \mathrm{ab}$ \\
\hline \multicolumn{6}{|c|}{ 3-wayANOVA } \\
\hline \multicolumn{3}{|c|}{ Strength MS (A) } & $0.599 \mathrm{~ns}$ & $0.000 * * *$ & $0.003 * *$ \\
\hline \multicolumn{3}{|c|}{ Sucrose level (B) } & $0.000 * * *$ & $0.074 \mathrm{~ns}$ & $0.000^{* * *}$ \\
\hline \multicolumn{3}{|c|}{ Mannitol concentration (C) } & $0.000 * * *$ & $0.000 * * *$ & $0.000 * * *$ \\
\hline \multicolumn{3}{|c|}{$(\mathrm{A}) *(\mathrm{~B})$} & $0.590 \mathrm{~ns}$ & $0.223 \mathrm{~ns}$ & $0.505 \mathrm{~ns}$ \\
\hline \multicolumn{3}{|c|}{$(\mathrm{A}) *(\mathrm{C})$} & $0.306 \mathrm{~ns}$ & $0.045^{*}$ & $0.001 * *$ \\
\hline \multicolumn{3}{|c|}{$(\mathrm{B}) *(\mathrm{C})$} & $0.083 \mathrm{~ns}$ & $0.327 \mathrm{~ns}$ & $0.042 *$ \\
\hline \multicolumn{3}{|c|}{$(\mathrm{A})^{*}(\mathrm{~B})^{*}(\mathrm{C})$} & $0.648 \mathrm{~ns}$ & $0.069 \mathrm{~ns}$ & $0.147 \mathrm{~ns}$ \\
\hline \multicolumn{6}{|c|}{ Rootstock: Gisela 6} \\
\hline \multirow{8}{*}{ full } & 30 & 0 & $18.245 \mathrm{bc}$ & $0.355 \mathrm{abc}$ & $7.057 \mathrm{a}$ \\
\hline & 30 & 5 & $17.053 \mathrm{abc}$ & $0.374 \mathrm{abc}$ & $6.756 \mathrm{a}$ \\
\hline & 30 & 10 & $12.301 \mathrm{a}$ & $0.298 \mathrm{abc}$ & $5.270 \mathrm{a}$ \\
\hline & 30 & 20 & $13.941 \mathrm{ab}$ & $0.316 \mathrm{abc}$ & $5.897 \mathrm{a}$ \\
\hline & 15 & 0 & $16.844 \mathrm{abc}$ & $0.451 \mathrm{c}$ & $7.159 \mathrm{a}$ \\
\hline & 15 & 5 & $11.391 \mathrm{a}$ & $0.418 \mathrm{bc}$ & $6.937 \mathrm{a}$ \\
\hline & 15 & 10 & $14.863 \mathrm{abc}$ & $0.277 \mathrm{ab}$ & $5.356 \mathrm{a}$ \\
\hline & 15 & 20 & $12.830 \mathrm{ab}$ & $0.266 \mathrm{ab}$ & $5.316 \mathrm{a}$ \\
\hline \multirow{8}{*}{$1 / 2$} & 30 & 0 & $17.202 \mathrm{abc}$ & $0.370 \mathrm{abc}$ & $6.917 \mathrm{a}$ \\
\hline & 30 & 5 & $12.352 \mathrm{a}$ & $0.234 \mathrm{a}$ & $4.839 \mathrm{a}$ \\
\hline & 30 & 10 & $20.169 \mathrm{c}$ & $0.346 \mathrm{abc}$ & $6.861 \mathrm{a}$ \\
\hline & 30 & 20 & $16.706 \mathrm{abc}$ & $0.419 \mathrm{bc}$ & $6.558 \mathrm{a}$ \\
\hline & 15 & 0 & $20.464 \mathrm{c}$ & $0.413 \mathrm{bc}$ & $7.231 \mathrm{a}$ \\
\hline & 15 & 5 & $13.182 \mathrm{ab}$ & $0.333 \mathrm{abc}$ & $5.622 \mathrm{a}$ \\
\hline & 15 & 10 & $14.849 \mathrm{abc}$ & $0.423 \mathrm{bc}$ & $6.800 \mathrm{a}$ \\
\hline & 15 & 20 & $18.618 \mathrm{bc}$ & $0.356 \mathrm{abc}$ & $6.458 \mathrm{a}$ \\
\hline \multicolumn{6}{|c|}{ 3-wayANOVA } \\
\hline \multicolumn{3}{|c|}{ Strength MS (A) } & $0.000 * * *$ & $0.003 * *$ & $0.004 * *$ \\
\hline \multicolumn{3}{|c|}{ Sucrose level (B) } & $0.897 \mathrm{~ns}$ & $0.379 \mathrm{~ns}$ & $0.743 \mathrm{~ns}$ \\
\hline \multicolumn{3}{|c|}{ Mannitol concentration (C) } & $0.236 \mathrm{~ns}$ & $0.495 \mathrm{~ns}$ & $0.490 \mathrm{~ns}$ \\
\hline \multicolumn{3}{|c|}{$(\mathrm{A}) *(\mathrm{~B})$} & $0.410 \mathrm{~ns}$ & $0.184 \mathrm{~ns}$ & $0.146 \mathrm{~ns}$ \\
\hline \multicolumn{3}{|c|}{$(\mathrm{A}) *(\mathrm{C})$} & $0.730 \mathrm{~ns}$ & $0.439 \mathrm{~ns}$ & $0.679 \mathrm{~ns}$ \\
\hline \multicolumn{3}{|c|}{$(\mathrm{B}) *(\mathrm{C})$} & $0.052 \mathrm{~ns}$ & $0.120 \mathrm{~ns}$ & $0.727 \mathrm{~ns}$ \\
\hline$(\mathrm{A}) *(\mathrm{~B}$ & $*(\mathrm{C})$ & & $0.805 \mathrm{~ns}$ & $0.758 \mathrm{~ns}$ & $0.880 \mathrm{~ns}$ \\
\hline
\end{tabular}

Means denoted by the same letter in each column and for each rootstock separately are not significantly different according to Duncan's multiple range test at $\mathrm{P} \leq 0.05$. ns - non significant effect $(\mathrm{P} \geq$ 0.05 ) according to 3-way ANOVA ( $n=13$ for CAB-6P and $n=22$ for Gisela 6$)$. 
Table 4 Effect of medium strength in inorganics, sucrose level, mannitol concentration and their interactions in a medium containing $1 \mathrm{mg} / \mathrm{IBA}$ on CAB-6P and Gisela 6 cherry rootstocks total carbohydrate and proline content in leaves and roots.

\begin{tabular}{|c|c|c|c|c|c|c|}
\hline $\begin{array}{l}\text { Strength MS } \\
\text { in inorganics }\end{array}$ & \begin{tabular}{|c} 
Sucrose \\
$(\mathrm{g} / \mathrm{l})$
\end{tabular} & $\begin{array}{c}\text { Mannitol } \\
(\mathrm{g} / \mathrm{l})\end{array}$ & \begin{tabular}{|c}
$\begin{array}{c}\text { Leaf carbohydrates } \\
(\mu \mathrm{mol} / \mathrm{g} \mathrm{F} . \mathrm{W} .)\end{array}$ \\
\end{tabular} & $\begin{array}{c}\text { Leaf proline } \\
(\mu \mathrm{mol} / \mathrm{g} \mathrm{F} . \mathrm{W} .)\end{array}$ & $\begin{array}{c}\text { Root carbohydrates } \\
(\mu \mathrm{mol} / \mathrm{g} \mathrm{F} . \mathrm{W} .)\end{array}$ & $\begin{array}{l}\text { Root proline } \\
(\mu \mathrm{mol} / \mathrm{g} \text { F.W. })\end{array}$ \\
\hline \multicolumn{7}{|c|}{ Rootstock: CAB-6P } \\
\hline \multirow{8}{*}{ full } & 30 & 0 & $51.207 \mathrm{a}$ & $2.850 \mathrm{a}$ & $42.030 \mathrm{a}$ & $0.936 \mathrm{a}$ \\
\hline & 30 & 5 & $76.033 \mathrm{~cd}$ & $3.016 \mathrm{a}$ & $83.304 \mathrm{~d}$ & $1.225 \mathrm{ab}$ \\
\hline & 30 & 10 & $103.520 \mathrm{fg}$ & $22.800 \mathrm{f}$ & $79.113 \mathrm{c}$ & $2.249 \mathrm{~d}$ \\
\hline & 30 & 20 & $68.866 \mathrm{bc}$ & $6.282 \mathrm{bcd}$ & $65.434 \mathrm{~b}$ & $1.909 \mathrm{~cd}$ \\
\hline & 15 & 0 & $55.611 \mathrm{ab}$ & $4.553 \mathrm{~b}$ & $47.542 \mathrm{a}$ & $1.475 \mathrm{bc}$ \\
\hline & 15 & 5 & 92.701 defg & $5.472 \mathrm{bc}$ & $183.827 \mathrm{f}$ & $1.969 \mathrm{~cd}$ \\
\hline & 15 & 10 & 99.003 efg & $22.139 \mathrm{f}$ & $93.114 \mathrm{e}$ & $5.956 \mathrm{f}$ \\
\hline & 15 & 20 & $76.250 \mathrm{~cd}$ & $10.489 \mathrm{de}$ & $67.038 \mathrm{~b}$ & $1.644 \mathrm{bc}$ \\
\hline \multirow{8}{*}{$1 / 2$} & 30 & 0 & $71.266 \mathrm{bcd}$ & $4.383 \mathrm{ab}$ & $43.148 \mathrm{a}$ & $1.134 \mathrm{ab}$ \\
\hline & 30 & 5 & 97.454 efg & 6.549 bcd & $67.303 \mathrm{~b}$ & $1.876 \mathrm{~cd}$ \\
\hline & 30 & 10 & $108.787 \mathrm{~g}$ & $6.744 \mathrm{bcd}$ & $67.837 \mathrm{~b}$ & $1.309 \mathrm{~b}$ \\
\hline & 30 & 20 & $75.748 \mathrm{~cd}$ & $16.099 \mathrm{e}$ & $70.117 \mathrm{bc}$ & $1.501 \mathrm{c}$ \\
\hline & 15 & 0 & $64.735 \mathrm{abc}$ & $3.223 \mathrm{a}$ & $40.828 \mathrm{a}$ & $0.945 \mathrm{a}$ \\
\hline & 15 & 5 & $86.437 \mathrm{def}$ & $12.207 \mathrm{de}$ & $60.902 \mathrm{~b}$ & $2.778 \mathrm{e}$ \\
\hline & 15 & 10 & $78.900 \mathrm{de}$ & $11.732 \mathrm{de}$ & $57.592 \mathrm{~b}$ & $1.350 \mathrm{~b}$ \\
\hline & 15 & 20 & $73.423 \mathrm{~cd}$ & $9.898 \mathrm{cde}$ & $70.913 \mathrm{c}$ & $3.066 \mathrm{e}$ \\
\hline \multicolumn{7}{|c|}{ 3-wayANOVA } \\
\hline \multicolumn{3}{|c|}{ Strength MS (A) } & $0.000 * * *$ & $0.001 * *$ & $0.002 * *$ & $0.000 * * *$ \\
\hline \multicolumn{3}{|c|}{ Sucrose level (B) } & $0.000 * * *$ & $0.000 * * *$ & $0.001 * *$ & $0.000 * * *$ \\
\hline \multicolumn{3}{|c|}{ Mannitol concentration (C) } & $0.797 \mathrm{~ns}$ & $0.000 * * *$ & $0.280 \mathrm{~ns}$ & $0.000^{* * *}$ \\
\hline \multicolumn{3}{|c|}{$(\mathrm{A})^{*}(\mathrm{~B})$} & $0.056 \mathrm{~ns}$ & $0.157 \mathrm{~ns}$ & $0.261 \mathrm{~ns}$ & $0.482 \mathrm{~ns}$ \\
\hline \multicolumn{3}{|c|}{$(\mathrm{A}) *(\mathrm{C})$} & $0.000 * * *$ & $0.002 * *$ & $0.084 \mathrm{~ns}$ & $0.000 * * *$ \\
\hline \multicolumn{3}{|c|}{$(\mathrm{B})^{*}(\mathrm{C})$} & $0.829 \mathrm{~ns}$ & $0.000 * * *$ & $0.261 \mathrm{~ns}$ & $0.000 * * *$ \\
\hline \multicolumn{3}{|c|}{$\begin{array}{r}(\mathrm{A}) *(\mathrm{~B}) *(\mathrm{C}) \\
\end{array}$} & $0.317 \mathrm{~ns}$ & $0.010 * *$ & $0.129 \mathrm{~ns}$ & $0.000 * * *$ \\
\hline \multicolumn{7}{|c|}{ Rootstock: Gisela 6} \\
\hline \multirow{8}{*}{ full } & 30 & 0 & $25.578 \mathrm{ab}$ & $2.801 \mathrm{ab}$ & $38.320 \mathrm{abcd}$ & $1.385 \mathrm{a}$ \\
\hline & 30 & 5 & $28.264 a b c$ & $2.619 \mathrm{ab}$ & $66.995 \mathrm{fg}$ & $2.173 a b c$ \\
\hline & 30 & 10 & $25.941 \mathrm{ab}$ & $7.865 \mathrm{ef}$ & 50.800 bcdef & $4.255 \mathrm{~d}$ \\
\hline & 30 & 20 & $23.942 \mathrm{ab}$ & 4.729 cde & $34.019 \mathrm{abc}$ & $1.669 \mathrm{abc}$ \\
\hline & 15 & 0 & $38.220 \mathrm{cde}$ & $6.288 \mathrm{de}$ & 39.108 abcde & $1.476 \mathrm{ab}$ \\
\hline & 15 & 5 & $29.819 \mathrm{abcd}$ & $10.255 \mathrm{f}$ & $57.248 \mathrm{ef}$ & $2.375 \mathrm{c}$ \\
\hline & 15 & 10 & 35.332 bcde & $10.904 \mathrm{f}$ & 52.477 cdef & $5.924 \mathrm{e}$ \\
\hline & 15 & 20 & $25.840 \mathrm{ab}$ & $3.716 \mathrm{ab}$ & $33.026 \mathrm{ab}$ & $1.886 \mathrm{abc}$ \\
\hline \multirow{8}{*}{$1 / 2$} & 30 & 0 & $39.895 \mathrm{de}$ & $3.547 \mathrm{ab}$ & 39.673 abcde & $1.392 \mathrm{a}$ \\
\hline & 30 & 5 & $22.508 \mathrm{a}$ & $5.651 \mathrm{cde}$ & 39.950 abcde & $2.331 \mathrm{bc}$ \\
\hline & 30 & 10 & $45.146 \mathrm{e}$ & $3.333 \mathrm{ab}$ & $76.061 \mathrm{~g}$ & $1.729 \mathrm{abc}$ \\
\hline & 30 & 20 & $28.284 \mathrm{abc}$ & $3.099 \mathrm{ab}$ & $53.789 \mathrm{def}$ & $1.924 \mathrm{abc}$ \\
\hline & 15 & 0 & $34.039 \mathrm{abcd}$ & $2.398 \mathrm{a}$ & 40.902 abcde & $1.665 \mathrm{abc}$ \\
\hline & 15 & 5 & $32.121 \mathrm{abcd}$ & 5.761 cde & $26.769 \mathrm{a}$ & $1.483 \mathrm{ab}$ \\
\hline & 15 & 10 & $30.687 \mathrm{abcd}$ & $2.729 \mathrm{ab}$ & $59.968 \mathrm{fg}$ & $1.950 \mathrm{abc}$ \\
\hline & 15 & 20 & $30.546 \mathrm{abcd}$ & $3.742 \mathrm{~cd}$ & 41.592 abcde & $1.995 \mathrm{abc}$ \\
\hline \multicolumn{7}{|c|}{ 3-wayANOVA } \\
\hline \multicolumn{3}{|c|}{ Strength MS (A) } & $0.001 * *$ & $0.000 * * *$ & $0.216 \mathrm{~ns}$ & $0.000 * * *$ \\
\hline \multicolumn{3}{|c|}{ Sucrose level (B) } & $0.391 \mathrm{~ns}$ & $0.033^{*}$ & $0.000 * * *$ & $0.000 * * *$ \\
\hline \multicolumn{3}{|c|}{ Mannitol concentration (C) } & $0.003 * *$ & $0.003 * *$ & $0.010 * *$ & $0.000 * * *$ \\
\hline \multicolumn{3}{|c|}{$(\mathrm{A})^{*}(\mathrm{~B})$} & $0.196 \mathrm{~ns}$ & $0.003 * *$ & $0.369 \mathrm{~ns}$ & $0.000 * * *$ \\
\hline \multicolumn{3}{|c|}{$(\mathrm{A}) *(\mathrm{C})$} & $0.012 *$ & $0.046^{*}$ & $0.781 \mathrm{~ns}$ & $0.000 * * *$ \\
\hline & 3)*(C) & & $0.493 \mathrm{~ns}$ & $0.044 *$ & $0.037 *$ & $0.000 * * *$ \\
\hline$(\mathrm{A})^{3}$ & $(\mathrm{~B}) *(\mathrm{C})$ & & $0.581 \mathrm{~ns}$ & $0.015^{*}$ & $0.283 \mathrm{~ns}$ & $0.000 * * *$ \\
\hline
\end{tabular}


It is possible that at high sugar concentration, rooting reduces the ability of buds to multiply by diverting most nutrients to root formation rather than to bud formation to overcome the expected water stress under these higher concentrations.

In the absence of mannitol from the culture medium, higher rooting percentages were recorded for CAB-6P explants with $30 \mathrm{~g} / \mathrm{l}$ sucrose in half MS or with $15 \mathrm{~g} / \mathrm{l}$ sucrose in full MS medium. Khan et al. (1999) found that the increase in sucrose concentration (from 10 to $30 \mathrm{~g} / \mathrm{l}$ ) was positively correlated with the rooting percentage and root number in Syzygium alternifolium, however, sucrose concentrations higher than $40 \mathrm{~g} / \mathrm{l}$ inhibited overall rooting response. On the other hand, in Gisela 6, the rhizogenetic capacity of the explants was greater with 30 $\mathrm{g} / \mathrm{l}$ sucrose in full MS or $15 \mathrm{~g} / \mathrm{l}$ sucrose in half MS medium. In Eucalyptus globules and Eucalyptus saligna, increase of sucrose level from 30 to $60 \mathrm{~g} / \mathrm{l}$ did not influence root number and rooting percentage considerably (da Rocha Corrêa et al. 2005).

Root elongation of both $\mathrm{CAB}-6 \mathrm{P}$ and Gisela 6 microcuttings was diminished when the strength of the medium in inorganics was reduced by half. The promotory effect of mineral concentration of the culture medium on rooting can be attributed to the participation of inorganic ions in processes regulating hormonal balance (Amzallag et al., 1992). The favourable effect of a diluted mineral solution on rooting can be explained by the reduction of nitrogen concentration (Driver and Suttle 1987). Dimassi-Theriou (1995) reported that reducing mineral concentration of the MS medium to half the normal value increased rooting percentage and stimulated root elongation of the GF 677 rootstock in vitro. Ruzic et al. (1984) have proposed the use of MS medium at half of normal strength for rooting improvement of the GF 677 rootstock shoots. Moncousin (1988) suggested that the dilution of salt concentration to half prepare the plants in the tubes for better adaptation to the acclimatisation medium, while shoot growth and leaf size were increased. Reducing mineral concentration of MS medium to half the normal value increased the rooting percentage, root number and root elongation of PR 204/84 (Prunus persica x P. amygdalus) (Fotopoulos and Sotiropoulos 2005). Root length of Gisela 6 explants was increased along with an increase in sucrose level (15 to $30 \mathrm{~g} / \mathrm{l})$ in full MS medium. Our findings are in line with those obtained in Hypericum perforatum (Cui et al. 2010), in E. globules and E. saligna (da Rocha Corrêa et al. 2005) and S. alternifolium (Khan et al. 1999). Similarly, El-Karzaz et al. (1997) found that in mulberry (Morus alba L.) plants root formation on in vitro shoots was most extensive on MS medium supplemented with $30 \mathrm{~g} / \mathrm{l}$ sucrose.

In Gisela 6 explants grown on half MS medium, the increase in sucrose level from 15 to $30 \mathrm{~g} / \mathrm{l}$ led to a significant decrease in root fresh weight. In Hyoscyamus niger L., 15 or $30 \mathrm{~g} / \mathrm{l}$ sucrose produced good root biomass while higher concentrations had a negative effect (Hong et al. 2010). Sucrose generally exerts osmotic pressure and influences productivity of plants as a carbon source. In CAB-6P, on the other hand, non substantial fluctuations were observed in root fresh weight due to alterations in the MS medium regarding its sucrose and 
inorganics levels. Our results in Gisela 6 are in tune with Kevers et al. (1999), who reported $30 \mathrm{~g} / \mathrm{l}$ sucrose to be optimum for root biomass production in Panax ginseng and $P$. quinquefolium.

In CAB-6P explants, the higher sucrose level $(30 \mathrm{~g} / \mathrm{l})$ and medium strength (full MS) promoted better shoot length and shoot fresh weight whereas in Gisela $6,15 \mathrm{~g} / \mathrm{l}$ sucrose + half MS gave better results. In micropropagated potato plantlets (Mohamed and Alsadon 2010) and in date palm (Phoenix dactylifera L.) cv. Khanezi (Al-Khateeb, 2001) increasing sucrose concentrations significantly increased plantlet height and shoot fresh weight. In CAB-6P, the supplementation of the full MS medium containing $30 \mathrm{~g} / 1$ sucrose with $5 \mathrm{~g} / \mathrm{l}$ mannitol positively influenced shoot length. On the other hand, Fortes and Scherwinski-Pereira (2001) in potato, Moges et al. (2003) in chrysanthemum and Shibli et al. (1999) in bitter almond found that mannnitol caused a reduction in shoot growth compared to sucrose. In olive (Olea europaea L.), however, mannitol gave higher shoot length than sucrose (García et al. 2002).

In CAB-6P, callus fresh weight was greatest in the half MS medium supplemented with $30 \mathrm{~g} / \mathrm{l}$ sucrose and $5 \mathrm{~g} / \mathrm{l}$ mannitol. Mannitol increased callus fresh weight when added in the full MS medium with $15 \mathrm{~g} / 1$ sucrose. In $P$. dactylifera leaf explants cultured in vitro, callus fresh weight was increased with sucrose concentration up to $0.1 \mathrm{M}$ but then declined (Asemota et al. 2007). In Gisela 6, half MS supplemented with $15 \mathrm{~g} / \mathrm{l}$ sucrose (mannitol-free) exhibited greater callus fresh weight. Similarly, in strawberry when sucrose concentration was raised from 30 to $90 \mathrm{~g} / \mathrm{l}$ callus fresh weight was decreased (Gerdakaneh et al. 2010). According to Gerdakaneh et al. (2009), low sucrose concentration is much more effective than high levels on callus fresh weight as the rise of sucrose concentration decreases callus fresh weight and this capacity could be attributed to an osmotic effect. In CAB-6P, the increase in sucrose concentration from 15 to $30 \mathrm{~g} / \mathrm{l}$ led to lower callus induction frequencies. Similar findings were reported for Gisela 6 where callus induction frequency was greatest in the simultaneous effect half MS $+30 \mathrm{~g} / \mathrm{l}$ sucrose $+5 \mathrm{~g} / \mathrm{l}$ mannitol. In the apple rootstock Jork 9, sucrose promoted callus formation (Pawlicki and Welander 1995).In CAB-6P, mannitol led to depleted chlorophyll, carotenoid and porphyrin levels in half MS medium regardless sucrose content, except for the half $\mathrm{MS}+30 \mathrm{~g} / \mathrm{l}$ sucrose +5 $\mathrm{g} / \mathrm{l}$ mannitol combination treatment where an increase in total chlorophyll content was observed. In accordance, mannitol decreased chlorophyll and carotenoid content of sugarcane vitroplants (Cha-Um and Kirdmanee 2008). In Gisela 6, mannitol decreased carotenoid content when explants treated with $15 \mathrm{~g} / \mathrm{l}$ sucrose (full MS). A possible explanation for this decrease according to Vitova et al. (2002) is that mannitol creates an osmotic stress which strongly inhibits the plant cell, tissue and organ growth mainly by impairing the gain of photoassimilates e.g. by inducing stomata closure or lowering the activity of photosynthetic enzymes. In Gisela 6, on the other hand, fifty percent decrease in both macroand microelements concentration of MS medium supplemented with $15 \mathrm{~g} / \mathrm{l}$ sucrose raised chlorophyll content. Sucrose linearly increases the level of reducing sugars, starch, and total chlorophyll in citrus plantlets (Hazarika et al. 
2000). In CAB-6P, higher chlorophyll levels were recorded in half MS medium supplemented with $15 \mathrm{~g} / \mathrm{l}$ sucrose or $30 \mathrm{~g} / \mathrm{l}$ sucrose $+5 \mathrm{~g} / \mathrm{l}$ mannitol compared to the full MS one. Different results were reported by Mohamed and Alsadon (2010) and Serret et al. (2001) who observed a positive correlation between chlorophyll content and sucrose concentration. The higher chlorophyll content observed in the rooting phase in plants growing at lower sucrose concentrations such as in Gisela 6 cherry rootstock of our study may indicate that such plants could present a higher photosynthetic capacity, facilitating the acclimatization.

In $\mathrm{CAB}-6 \mathrm{P}$, mannitol resulted in elevated carbohydrate and proline levels in both leaves and roots regardless sucrose level (15 or $30 \mathrm{~g} / \mathrm{l})$ and concentration of the MS medium in inorganics (full or half). Accordingly, mannitol considerably augmented endogenous proline of micropropagated sugarcane (Cha-Um and Kirdmanee 2008). Vitova et al. (2002) states that under high mannitol concentration, osmotic stress causes restriction of mannitol utilization and lowering availability of energy and carbon source. In Gisela 6, mannitol increased leaf proline content of leaves grown in half MS medium with $15 \mathrm{~g} / \mathrm{l}$ sucrose, whereas in roots mannitol at $10 \mathrm{~g} / \mathrm{l}$ raised both proline (full MS) and carbohydrate content (half MS) irrespective sucrose level. According to Ahmad et al. (2007) sugars are perceived by cells as chemical signals in vitro with very high concentration acting as stressing agents.

Proline accumulation in stressed plants is one of the vital compatible solutes to function in cellular osmotic adjustment and scavenge detoxify oxidants (Seki et al. 2007) and its degradation can provide carbon, nitrogen and energy source after stress (Hare et al. 1999). On the contrary, the increase in sucrose level from 15 to $30 \mathrm{~g} / \mathrm{l}$ led to depleted proline levels in Gisela 6 leaves and CAB$6 \mathrm{P}$ roots (full MS) indicating mechanism of osmoregulation and osmotic adjustment located only in leaves for Gisela 6 and only in roots for CAB-6P. The carbohydrate content of Gisela 6 leaves was higher in half MS medium supplemented with $30 \mathrm{~g} / \mathrm{l}$ sucrose. Sucrose may facilitate growth and development due to its impact on the adjustment of cell osmolarity as reported by Khuri and Moorby (1995). In CAB-6P roots, the increase in sucrose level from 15 to $30 \mathrm{~g} / \mathrm{l}$ resulted in depleted proline levels. Our findings are in disagreement with those presented in micropropagated potato plantlets (Solanum tuberosum L. cv Norland) (Badr et al. 2011) and in strawberry (Gerdakaneh et al. 2010) where the amount of free proline was increased as a response to the increase in sucrose concentration. According to Badr et al. (2011), the presence of sucrose in the culture medium causes an osmotic stress which leads to the build up of compatible solutes, such as proline, sugars and sugar alcohols in plantlets allowing them to absorb water under these conditions.

\section{CONCLUSIONS}

It seems that mannitol concentration, sucrose level and medium strength in inorganics are involved in photosynthetic apparatus, influencing leaf chlorophyll, carotenoid or porphyrin content and participating in carbohydrate biosynthesis and metabolism as well as in proline accumulation in both leaves and roots. It is 
obvious that each cherry rootstock has its own specific requirements in macroand micronutrients, in sucrose as the main carbon and energy source and in mannitol as a supplement, all in combination for optimum rooting and shoot growth performance under in vitro conditions.

Therefore, the different responses between the two cherry rootstocks to rooting, vegetative and callusing traits as well as to various biochemical parameters are genotype-dependent.

\section{ACKNOWLEDGEMENTS}

We would like to express our sincere gratitude to Fitotechniki Plant Tissue Culture Laboratory - Xylogiannis Bros Co., Arta, Greece and Angelos Xylogiannis for kindly providing the CAB-6P (P. cerasus L.) and Gisela 6 (P. cerasus x P. canescens) vitroplants; also our thanks to Sofia Kuti and Vasiliki Tsakiridou for technical assistance.

The authors gratefully acknowledge the financial support of the Aristotle University of Thessaloniki.

\section{REFERENCES}

Ahmad, T., Abbasi, N.A., Hafiz, I.A. \& Ali, A. (2007): Comparison of sucrose and sorbitol as main carbon energy source in morphogenesis of peach rootstock GF677. Pak. J. Bot., 39: 1264-1275.

Al-khateeb, A.A. (2001): Influence of different carbon sources and concentrations on in vitro root formation of date palm (Phoenix dactylifera L.) cv Khanezi. Zagazig J. Agric. Res., 28: 597-608.

Amzallag, G.N., Lerner, H.R. \& Poljakoff-Mayber, M. (1992): Interaction between mineral nutrients, cytokinin and gibberillic acid during growth of sorghum at high $\mathrm{NaCl}$ salinity. J. Exp. Bot., 43: 81-87.

Asemota, O., Eke, C.R. \& Odewale, J.O. (2007): Date palm (Phoenix dactylifera L.) in vitro morphogenesis in response to growth regulators, sucrose and nitrogen. Afr. J. Biotechnol., 6: 2353-2357.

Badr, A., Angers, P. \& Desjardins, Y. (2011): Metabolic profiling of photoautotrophic and photomixotrophic potato plantlets (Solanum tuberosum) provides new insights into acclimatization. Plant Cell Tiss. Organ Cult., 107: 13-24.

Calamar, A. \& De Klerk, G.J. (2002): Effect of sucrose on adventitious root regeneration in apple. Plant Cell Tiss. Organ Cult., 70: 207-212.

Cha-Um, S. \& Kirdmanee, C. (2009): Proline accumulation, photosynthetic abilities and growth characters of sugarcane (Saccharum officinarum L.) plantlets in response to iso-osmotic salt and water-deficit stress. Agric. Sci. China, 8: 51-58.

Cui, X.H., Murthy, H., Wu, C.H. \& Paek, K.Y. (2010): Sucrose-induced osmotic stress affects biomass, metabolite, and antioxidant levels in root suspension cultures of Hypericum perforatum L. Plant Cell Tiss. Organ Cult., 103: 7-14.

da Rocha Corrêa, L., Paim, D.C., Schwambach, J. \& Fett-Neto, A.G. (2005): Carbohydrates as regulatory factors on the rooting of Eucalyptus saligna Smith and Eucalyptus globulus Labill. Plant Growth Regul., 45: 63-73.

Dimassi-Theriou, K. (1995): In vitro rooting of rootstock GF 677 (P. persica x P. amygdalus) as influenced by mineral concentration of the nutrient medium and type of culture-tube sealing material. J. Hortic. Sci., 70: 105-108.

Dimassi-Theriou, K. \& Economou, A. (1993): The effect of the explant type and the nutrient substrate composition on shoot production in in vitro cultures of the 
rootstock GF-677 (P. persica $\mathrm{x}$ P. amygdalus). Aristotle University of Thessaloniki, Thessaloniki, Greece, Scientific Annals, pp. 31-35.

Driver, J.A. \& Suttle, G.R. (1987): Nursery handling of propagles. In J.M. Bonga \& D.J. Durzan, eds. Cell and tissue culture in forestry, pp. 320-335. Dortrecht, The Netherlands, Springer.

El-Kazzaz, A., Fahmy, G.E., Bahr, M.K., Hanafy, M.S. \& Moemen, S.H. (1997): Propagation of mulberry (Monus alba L.) via tissue culture. Bull. Nat. Res. Center Cairo, 22: 175-188.

Flora, L.L. \& Madore, M.A. (1993): Stachyosa and mannitol transport in olive (Olea europaea L.). Planta, 189: 484-490.

Fortes, G.R. \& Scherwinski-Pereira, J.E. (2001): Preservação in vitro de batata com ácido acetilsalicílico e duas fontes de carboidrato. Pesq. Agropec. Bras., 36: 1261-1264.

Fotopoulos, S. \& Sotiropoulos, T.E. (2005): In vitro rooting of PR 204/84 rootstock (Prunus persica $\mathrm{x}$ P. amygdalus) as influenced by mineral concentration of the culture medium and exposure to darkness for a period. Agronomy Res., 3: 3-8.

Fowler, M.R. (2000): Plant cell culture, laboratory techniques. In R.E. Spier, ed. Encyclopedia of cell technology, pp. 994-1002. New York, USA, John Wiley \& Sons.

Fuentes, S.R.L., Calheiros, M.B.P., Manetti-Filho, J. \& Vieira, L.G.E. (2000): The effect of silver nitrate and different carbohydrate sources on somatic embryogenesis in Coffea canephora. Plant Cell Tiss. Organ Cult., 60: 5-13.

García, J.L., Troncoso, J., Sarmiento, R. \& Troncoso, A. (2002): Influence of carbon source and concentration on the in vitro development of olive zygotic embryos and explants raised from them. Plant Cell Tiss. Organ Cult., 69: 95-100.

Gerdakaneh, M., Mozafari, A.A., Khalighi, A. \& Sioseh-Mardah, A. (2010): The effects of exogenous proline and osmotic stress on morpho-biochemical parameters of strawberry callus. Afr. J. Biotechnol., 9: 3775-3779.

Gerdakaneh, M., Mozafari, A.A., Khalighi, A. \& Sioseh-Mardah, A. (2009): The effects of carbohydrate source and concentration on somatic embryogenesis of strawberry (Fragaria x ananassa Duch.). Am.-Eur. J. Agric. Environ. Sci. 6: 76-80.

Hare, P.D., Cress, W.A. \& Van Staden, J. (1999): Proline synthesis and degradation: A model system for elucidating stress related signal transduction. J. Exp. Bot., 50: 413-434.

Hong, M.L.K., Bhatt, A., Shuping, N. \& Keng, C.L. (2010): Optimization of root proliferation medium for Hyoscyamus niger L. J. Med. Plants Res., 4: 2710-2718.

Ibrahim, A.I. (1999): Somaclonal variation during micropropagation of date palm via embryogenesis. In First International Conference in Egypt on Plant Tissue Culture and its Applications, pp. 189-199.

Kevers, C., Jacques, P., Thonart, P. \& Gaspar, T. (1999): In vitro root cultures of Panax ginseng and P. quinquefolium. Plant Growth Regul., 27: 173-178.

Khan, A.A., McNeilly, T. \& Collins, C. (2000): Accumulation of amino acids, proline, and carbohydrates in response to aluminium and manganese stress in maize. J. Plant Nutr., 23: 1303-1314.

Khan, P.S.S.V., Hausman, J.F. \& Rao, K.R. (1999): Effect of agar, MS medium strength, sucrose and polyamines on in vitro rooting of Syzygium alternifolium. Biol. Plant., 42: 333-340.

Khuri, S. \& Moorby, J. (1995): Investigation into the role of sucrose in potato cv. Estima microtuber production in vitro. Ann. Bot., 75: 295-303.

Langford, P.J. \& Wainwright, H. (1987): Effects of sucrose concentration on the photosynthetic ability of rose shoots in vitro. Ann. Bot., 60: 633-640. 
La Rosa, P.C., Hasegawa, P.M. \& Bressan, R.A. (1984): Photoautotrophic potato cells: Transition from heterotrophic to autotrophic growth. Physiol. Plant., 61: 279-286.

Leva, A.R., Petruccelli, R., Muleo, R., Goretti, R. \& Bartolini, G. (1995): Influenza di fattori trofici, regolativi e condizioni del mezzo nutritivo sulla coltura in vitro di diverse cultivar di olivo. Atti del Convegno: L'Olivicoltura Mediterranea: stato e prospettive della coltura e della ricerca. Instituto Sperimentale perla Olivicoltura, Rende, Italy, pp. 239-248.

Lichenthaler, H.K. (1987): Chlorophylls and carotenoids: Pigments of photosynthetic biomembranes. Methods Enzymol., 148: 350-382.

Manzanera, J.A. \& Pardos, J.A. (1990): Micropropagation of juvenile and adult Quercus suber L. Plant Cell Tiss. Organ Cult., 21: 1-8.

Moges, A.D., Karam, N.S. \& Shibli, R.A. (2003): Slow growth in vitro preservation of African violet (Saintpaulia ionantha Wendl.) shoot tips. Adv. Hort. Sci. 17: 1-8.

Mohamed, M.A.H. \& Alsadon, A.A. (2010): Influence of ventilation and sucrose on growth and leaf anatomy of micropropagated potato plantlets. Sci. Hortic., 123: 295-300.

Moncousin, C. (1988): Adventitious rhizogenesis control: new developments. Acta Hortic., 230: 97-104.

Murashige, T. \& Skoog, F. (1962): A revised medium for rapid growth and bioassays with tobacco tissue cultures. Physiol. Plant., 15: 473-497.

Pawlicki, N. \& Welander, M. (1995): Influence of carbohydrate source, auxin concentration and time of exposure on adventitious rooting of the apple rootstock Jork 9. Plant Sci.,106: 167- I76.

Pierik, R.L.M. (1997): In vitro cultures of higher plants. Martinus Nijhoff Publishers, Dordrecht.

Plummer, D.T. (1987): Practical biochemistry. 3rd edn. pp. 179-180. New York, NY: McGraw-Hill Book Company.

Porra, R.J., Thompson, W.A. \& Kriedelman, P.E. (1989): Determination of accurate extraction and simultaneously equation for assaying chlorophyll a and $\mathrm{b}$ extracted with different solvents: verification of the concentration of chlorophyll standards by atomic absorption spectroscopy. Biochim. Biophys. Acta, 975: 384-394.

Premkumar, A., Barcelo-Munoz, A., Quesada, M.A., Mercado, J.A. \& Pliego-Alfaro, E. (2003): Influence of sucrose concentration on in vitro rooting, growth, endogenous sugars and ex vitro survival of juvenile avocado. J. Hort. Sci. Biotechnol., 78: 4650.

Pua, E.C. \& Chong, C. (1985): Regulation in-vitro shoot and root regeneration in 'Macspur' apple by sorbitol (D-glycitol) and related carbon sources. J. Am. Soc. Hortic. Sci., 110: 705-709.

Ruzic, D., Rosati, P. \& Marino, G. (1984): Effecto dei figoregolatori nella micripropagatione dell' ibrido pesco x mandorlo GF 677. Riv. Ortflorofrutt. It., 68: 413-422.

Schneider, F. (2005): Effect of different cultural conditions on micropropagation of rose (Rosa sp. L.) and globe artichoke (Cynara scolymus L.). Technische Universität München, München.

Seki, M., Umezawa, T., Urano, K. \& Shinozaki, K. (2007): Regulatory metabolic networks in drought stress responses. Curr. Opin. Plant Biol., 10: 296-302.

Serret, M.D., Trillas, M.I. \& Araus, J.L. (2001): The effect of in vitro conditions on the pattern of photoinhibition during acclimation of gardenia plantlets to ex vitro conditions. Photosynthetica, 39: 67-73. 
Shibli, R.A., Shatnawi, M.A., Ajlouni, M.M., Jaradat, A. \& Adham, Y. (1999): Slow growth in vitro conservation of bitter almond (Amygdalus communis L.). Adv. Hort. Sci., 13: 133-134.

Swedlund, B. \& Locy, R.D. (1993): Sorbitol as the primary carbon source for the growth of embryogenic callus of maize. Plant Physiol., 103: 1339-1346.

Troll, W. \& Lindsley, J. (1955): A photometric method for determination of proline. J. Biol. Chem., 215: 655-660.

Vitova, L., Stodulkova, E., Bartonickova, A. \& Lipavska, H. (2002): Mannitol utilization by celery (Apium graveolens) plants grown under different conditions in vitro. Plant Sci., 163: 907-916.

Vu, J.C.V., Neidz, R.P. \& Yelonosky, G. (1993): Glycerol stimulation of chlorophyll synthesis, embryogenesis, and carboxylation and sucrose metabolism enzymes in nucellar callus of 'Hamlin' sweet orange. Plant Cell Tiss. Organ Cult., 33: 75-80.

Yang, C.M., Chang, K.W., Yin, M.H. \& Hung, H.M. (1998): Methods for the determination of the chlorophylls and their derivatives. Taiwania, 43: 116-122.

Wintermans, J.F.G.M. \& De Mots, A. (1965): Spectrophotometric characteristics of chlorophylls $\mathrm{a}$ and $\mathrm{b}$ and their pheophytins in ethanol. Biochim. Biophys. Acta., 109: 448-453. 